8-1-2011

\title{
In Vitro and In Vivo Effects of A Cyclooxygenase-2 Inhibitor Nimesulide Analog JCC76 in Aromatase Inhibitors-Insensitive Breast Cancer Cells
}

\author{
Bo Zhong \\ Cleveland State University \\ Xiaohan Cai \\ Cleveland State University \\ Xing Yi \\ Cleveland State University \\ Aimin Zhou \\ Cleveland State University, A.ZHOU@csuohio.edu \\ Shiuan Chen \\ Beckman Research Institute of the Cty of Hope
}

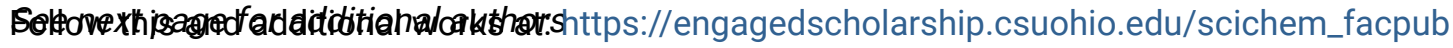

Part of the Chemistry Commons

How does access to this work benefit you? Let us know!

\section{Recommended Citation}

Zhong, Bo; Cai, Xiaohan; Yi, Xing; Zhou, Aimin; Chen, Shiuan; and Su, Bin, "In Vitro and In Vivo Effects of A Cyclooxygenase-2 Inhibitor Nimesulide Analog JCC76 in Aromatase Inhibitors-Insensitive Breast Cancer Cells" (2011). Chemistry Faculty Publications. 394.

https://engagedscholarship.csuohio.edu/scichem_facpub/394

This Article is brought to you for free and open access by the Chemistry Department at EngagedScholarship@CSU. It has been accepted for inclusion in Chemistry Faculty Publications by an authorized administrator of EngagedScholarship@CSU. For more information, please contact library.es@csuohio.edu. 
Authors

Bo Zhong, Xiaohan Cai, Xing Yi, Aimin Zhou, Shiuan Chen, and Bin Su 


\title{
Increased Severity of HSV-1 Keratitis and Mortality in Mice Lacking the 2-5A-dependent RNase L Gene
}

\author{
Xiaodong Zheng, ${ }^{1,3}$ Robert H. Silverman, ${ }^{2}$ Aimin Zhou, ${ }^{2}$ Tomoko Goto, ${ }^{1,3}$ \\ Byoung Se Kwon, ${ }^{1}$ Herbert E. Kaufman, ${ }^{1}$ and James M. Hill ${ }^{1}$
}

Purpose. The $2^{\prime}, 5^{\prime}$-oligoadenylate-dependent RNase $\mathrm{L}$ gene functions in the interferon-inducible RNA decay pathway known as the 2-5A system. The purpose of this study was to determine whether the absence of this gene affects the pathogenesis of herpes simplex virus type 1 (HSV-1) ocular infection in the mouse.

Methods. HSV-1 (strain McKrae) was applied bilaterally to unscarified corneas of RNase L-null mice and congenic controls. To evaluate the severity of herpetic keratitis, slit lamp examinations (SLE) were performed every other day for 14 days. To study corneal histology and apoptosis, HSV-1-inoculated RNase-L-null and congenic control mice, as well as mockinoculated mice (apoptosis negative control), were killed at 6 and 18 hours postinoculation (PI). Uninoculated mice that underwent corneal scarification (apoptosis positive control) were killed 2 hours after scarification. Eyes were dissected and the corneas processed for light and transmission electron microscopy and the TUNEL assay.

RESULTS. In comparison with the congenic control mice, RNase L-null mice showed significantly more severe herpetic keratitis (PI day 8, SLE score, mean \pm SEM: $3.27 \pm 0.10$ vs. $2.34 \pm 0.06$; $P<0.001$ ) and significantly higher mortality (PI day $14,70 \%$ vs. $20 \% ; P<0.001$ ). Few apoptotic cells were seen in HSV-1infected RNase L-null mice, although DNA fragmentation consistent with apoptosis was detected in the corneas of congenic control mice 6 and 18 hours after HSV-1 inoculation and in uninfected mice with scarified corneas. Signs of apoptosis were not present in the mock-infected corneas. Electron microscopic evidence of keratocytic apoptosis was detected only in the uninfected scarified corneas and the HSV-1-infected congenic control corneas.

Conclusions. The increased severity of ocular disease and increased mortality in the RNase L-null mice provides evidence, for the first time, that the $2-5 \mathrm{~A}$ system contributes to protection during ocular herpetic infection. The reduced frequency of apoptosis in these mice suggests that one possible mechanism for this protective effect could be the induction of apoptosis in corneal cells as a means of reducing the spread

From the ${ }^{1}$ Department of Ophthalmology, LSU Eye Center, Louisiana State University Health Sciences Center, New Orleans, Louisiana; and the ${ }^{2}$ Department of Cancer Biology, Lerner Research Institute, The Cleveland Clinic Foundation, Cleveland, Ohio.

${ }^{3}$ Present affiliation: Department of Ophthalmology, Ehime University School of Medicine, Ehime, Japan.

Supported in part by US Public Health Service Grants EY06311 (JMH), EY02672 (HEK), and EY02377 (LSU Eye Center Core Grant) from the National Eye Institute, and CA44059 (RHS) from the National Cancer Institute, National Institutes of Health, Bethesda, Maryland, and an unrestricted departmental grant (LSU Eye Center) from Research to Prevent Blindness, Inc., New York.

Submitted for publication February 7, 2000; revised June 20 and September 5, 2000; accepted September 12, 2000.

Commercial relationships policy: $\mathrm{N}$

Corresponding author: James M. Hill, LSU Eye Center, 2020 Gravier Street, Suite B, New Orleans, LA 70112-2234. jhill@1suhsc.edu of infectious virus. (Invest Ophthalmol Vis Sci. 2001;42: $120-126$ )

$\mathrm{H}$ erpes simplex virus type 1 (HSV-1) infection is one of the most intensively investigated of all infectious ocular diseases. Corneal infection with HSV-1 represents a significant clinical problem for its potential to cause blindness. ${ }^{1,2}$ In higher vertebrates, many cellular strategies have been developed to defend against viral invasion. The interferon (IFN) family of cytokines is known to be important in host defenses to viral infection, and the IFN-induced antiviral pathways have been investigated intensively. ${ }^{3-9}$ The evolution of intercellular communication has provided infected cells with the ability to signal uninfected cells that a virus had invaded the organism. Thus some cells undergo apoptosis or programmed cell death in the face of viral infection, a process that could be used by the host to limit viral invasion..$^{3,9-12}$ Similarly, HSV-1 infection of the corneal epithelium has been shown to induce apoptosis of underlying keratocytes. ${ }^{13}$ Specific viral proteins have also been suggested to be involved in anti-apoptotic effects ${ }^{14,15}$ or in negating antiviral functions of the host innate immune response (i.e., IFN). ${ }^{16,17}$

Levels of IFN- $\beta$ and IFN- $\gamma$ have been shown to be elevated in the cornea after viral infection. ${ }^{2,18-20}$ Involvement of the 2-5A system in the IFN-initiated antiviral scenario has been well elucidated..$^{3,4,7-12,21-31}$ In brief, IFN signals cells, leading to an increase in levels of the family of $2^{\prime}, 5^{\prime}$-oligoadenylate synthetases (OAS). Double-stranded RNA derived from viral replication intermediates and viral transcription activates OAS. Activated OAS converts ATP into unusual, short $2^{\prime}-5^{\prime}$ linked oligoadenylates called 2-5A. The $2-5 \mathrm{~A}$ binds to and activates RNase L, cleaving single-stranded RNA with moderate specificity for sites $3^{\prime}$ of UpUp and UpAp sequences. RNase L rapidly degrades both viral and cellular RNA, thus crippling the cell's ability to support viral replication. Involvement of the 2-5A system in the antiviral effect of IFN by means of induction of apoptosis has been reported in cell culture experiments as well as in an animal model containing a targeted disruption in the gene encoding RNase L (RNase L-null mouse). ${ }^{8,9,11,24,28,30,31}$

However, in vivo evidence for the antiviral function of the $2-5 \mathrm{~A}$ system is limited to studies of encephalomyocarditis virus. ${ }^{24}$ To our knowledge, there has been no report showing that the 2-5A system mediates an antiviral effect by induction of apoptosis in response to HSV-1 infection in any animal model. In this study, we used RNase L-null mice and congenic controls to investigate the possibility that the 2-5A system plays a role in mediating an antiviral effect in HSV-1 infection in the mouse eye.

\section{Methods}

\section{RNase L-Null Mice}

Six- to 8-week-old RNase L-null mice and congenic control mice were used. The genetic background of the RNase L-null and congenic control mice was $129 / 01 \mathrm{a} \times$ Swiss black. ${ }^{24}$ The construction of the RNase L gene-targeting vector and the generation of RNase L-null mice 
have been described. ${ }^{24}$ The RNase L-null mice and the congenic control mice were not visually distinguishable. All animals were handled in accordance with the ARVO Statement for the Use of Animals in Ophthalmic and Vision Research.

\section{Cells and Virus}

HSV-1 strain McKrae was propagated on primary rabbit kidney cell monolayers in minimal essential medium (GIBCO, Gaithersburg, MD) with $5 \%$ fetal bovine serum and titered on African green monkey kidney cells.

\section{Mouse Inoculation}

Each RNase L-null mouse and congenic control mouse was anesthetized with $150 \mu \mathrm{l}$ of a mixture of ketamine $(10 \mathrm{mg} / \mathrm{ml})$ and xylazine $(5$ $\mathrm{mg} / \mathrm{ml}$ ). Each eye received $5 \mu \mathrm{l}$ of a viral suspension containing either $2.5 \times 10^{5}$ pfu or $2.5 \times 10^{7}$ pfu of HSV-1 strain McKrae. The cornea was not scarified. Eyelids were closed and massaged gently for 20 seconds with care taken to avoid leakage of the inoculum. Mock inoculation was done by inoculating the cornea with cell culture medium in the same manner.

\section{Slit Lamp Examination}

Slit lamp examinations (SLE) with $0.1 \%$ fluorescein staining were performed in a masked manner before inoculation and every other day for 14 days postinoculation (PI). Epithelial lesions and stromal involvement were graded on a scale of 0 to 4 , as follows: 0 , normal cornea; 0.5 , punctate lesions; 1.0, dendritic lesions; 1.5 , geographic lesions with stromal edema; 2.0, stromal involvement, pupillary iris visible; 3.0, stromal involvement, pupillary iris invisible; and 4.0, severe stromal keratitis, peripheral iris invisible. Mean disease scores ( \pm SEM) were calculated for each group on each observation day (PI days 2, 4, 6, 8, 10,12 , and 14).

\section{Experimental Design}

To study the clinical manifestations, groups of age- and sex-matched RNase L-null and congenic control mice were inoculated bilaterally with HSV-1 strain McKrae. The severity of herpetic corneal lesions was monitored by SLE, and mortality was recorded.

To analyze apoptosis, six each of RNase L-null and congenic control mice were inoculated bilaterally with HSV-1 $\left(2.5 \times 10^{5}\right.$ pfu per eye), without corneal scarification. Six and 18 hours later, mice were killed, the eyes dissected, and the corneas processed for DNA fragmentation detection (TUNEL assay) and light and transmission electron microscopy (TEM). Corneas of two congenic control mice scarified with a sterile 30 -gauge needle in a $5 \times 5$ line crosshatch pattern served as apoptotic signal positive controls. Both mice were killed 2 hours after corneal scarification because this time point has been reported to be the peak of occurrence of keratocytic apoptosis after corneal wounding. ${ }^{32}$ Two additional congenic control mice received cell culture medium (mock inoculation). One mock-infected mouse was killed at 6 hours after inoculation and one at 18 hours, along with the HSV-1-infected mice, to serve as apoptotic signal negative controls.

\section{DNA Fragmentation Detection}

In situ DNA fragmentation detection was performed by the TUNEL assay. Whole mouse eyes were removed; all right eyes were immediately embedded in optimal cutting temperature (OCT) compound (Miles Laboratories, Elkhart, IN), and frozen in liquid nitrogen. Twenty $7-\mu \mathrm{m}$ thick sections (every fifth section of approximately 100 sections from each eye) that extended transversely across the central cornea of the mouse eye were collected and stained with the peroxidasebased TUNEL method, according to the manufacturer's instructions (ApopTag Plus Peroxidase In Situ Apoptosis Detection Kit; Intergen, Purchase, NY). Twenty sections were stained from each corneal specimen; 60 sections were stained for each group at each time point (6 hours and 18 hours). In general, the average numbers of corneal cells,
TABLE 1. Slit Lamp Examination of Herpetic Corneal Lesions on PI Day 8

\begin{tabular}{clrcrr}
\hline \multirow{2}{*}{ Experiment } & \multicolumn{1}{l}{$\begin{array}{l}\text { RNase } \\
\text { L-Null }\end{array}$} & \multicolumn{1}{c}{$\mathbf{S}^{*}$} & $\begin{array}{c}\text { Congenic } \\
\text { Control }\end{array}$ & \multicolumn{1}{c}{$\boldsymbol{S}^{*}$} & \multicolumn{1}{c}{$\boldsymbol{P} \boldsymbol{T}$} \\
\hline 1 & $3.67 \pm 0.11 \neq$ & $3 / 10$ & $3.33 \pm 0.18$ & $6 / 10$ & 0.815 \\
2 & $3.27 \pm 0.10$ & $12 / 30$ & $2.36 \pm 0.06$ & $26 / 30$ & $<0.001$ \\
\hline
\end{tabular}

In Experiment 1, 10 RNase L-null and 10 congenic control mice were inoculated with $2.5 \times 10^{7}$ pfu of HSV-1 strain McKrae. In Experiment 2, three separate experiments were performed, each involving 10 RNase L-null and 10 congenic control mice inoculated with a 100 -fold lower viral titer $\left(2.5 \times 10^{5} \mathrm{pfu}\right)$. Herpetic corneal lesions were scored (Scale $0-4$ ) by slit lamp biomicroscopy every other day for a period of 14 days. The results of the three separate experiments were similar, and the data were combined.

${ }^{*} \mathrm{~S}=$ Number of mice surviving on PI day $8 /$ total number inoculated.

† Student's $t$-test.

$\neq$ Mean \pm SEM.

as evidenced by counterstaining of the nuclei, were approximately the same on each section of cornea for the two groups (data not shown). The TUNEL-positive cells were readily recognized by dark brown labeling. The numbers of apoptotic cells in 10 nonoverlapping, full corneal thickness, randomly selected columns were counted in a masked fashion for each specimen. ${ }^{13}$ The diameter of each column was the $400 \times$ field of the microscope.

\section{Light and Transmission Electron Microscopy}

All left eyes from mice killed as described previously were fixed in Karnovsky fixative (3\% gluteraldehyde, $1 \%$ paraformaldehyde) overnight. The corneas were then dissected, fixed again in Karnovsky fixative for an additional 24 hours, postfixed in osmium tetroxide, dehydrated with ethanol and propylene oxide, and embedded in a mixture of Araldite 502 and Embed 812 (EMS, Fort Washington, PA). Semithin sections $(0.5 \mu \mathrm{m})$ were initially stained with $1 \%$ toluidine blue and examined by light microscopy. Finally, thin sections $(70 \mathrm{~nm})$ were cut, stained with $2 \%$ uranyl acetate and lead citrate solutions, and examined by transmission electron microscopy (Zeiss TEM 10C/CR; Oberkochen, Germany) at $100 \mathrm{kV}$.

\section{Statistical Analysis}

Mortality and slit lamp scores for the RNase L-null and congenic control mice were analyzed separately. Mortality was analyzed with Kaplan-Meier analysis; differences between the two curves were compared using the Mantel-Haenszel procedure. ${ }^{33}$ Differences between the slit lamp scores were evaluated using the Student's $t$-test on the scores for the RNase L-null and congenic control mice. $P<0.05$ defined significance. All data analyses were performed with computer software (Statistical Analysis System; SAS Institute, Cary, NC).

\section{Results}

\section{Clinical Observations}

Two sets of experiments were performed to examine the characteristics of acute HSV-1 corneal infection in RNase L-null and congenic control mice. In the first experiment, mice inoculated with HSV-1 at a high titer $\left(2.5 \times 10^{7}\right.$ pfu per eye $)$ had high mortality. Only 3 of 10 RNase L-null mice survived to PI day 8 , which represented the peak of severity of the corneal disease, whereas 6 of 10 congenic control mice survived to this time point. However, there was no significant difference in the severity of disease between the two groups: mean ( \pm SEM) SLE scores on PI day 8 for the three surviving RNase L-null mice and the six surviving congenic control mice were $3.67 \pm 0.11$ and $3.33 \pm 0.18$, respectively $(P=0.815$, Table 1$)$. 
In the second set of experiments, a 100-fold lower viral titer $\left(2.5 \times 10^{5} \mathrm{pfu}\right)$ was used. After inoculation, the corneas displayed punctate epithelial lesions and small dendritic lesions. On PI day 4, the dendritic appearance of the corneal lesions became typical, and stromal involvement was observed, mostly in the RNase L-null mice.

This set of experiments consisted of three separate experiments with 10 mice in each group in each experiment, for a total of 30 RNase L-null mice and 30 congenic control mice inoculated. All three of the experiments produced similar results, and the data from all three experiments were combined. In contrast to the results of the first experiment, the mean severity of the corneal lesions in the surviving animals on PI day 8 (the peak of corneal disease) was significantly greater in the RNase L-null mice $(N=12 / 30)$ than in the congenic controls $(N=26 / 30)$ (mean \pm SEM SLE scores: $3.27 \pm 0.10 \mathrm{vs}$. $2.36 \pm 0.06 ; P<0.001$; Table 1, Fig. 1A).

Mortality was significantly greater in the RNase L-null mice than in the congenic controls. By PI day 8, 18 of $30(60 \%)$ RNase L-null mice had died, whereas only 4 of 30 (13.3\%) congenic control mice had died $(P<0.001$, Fig. 1B). Furthermore, both mortality and the severity of ocular disease were significantly greater in the RNase L-null mice, compared with the congenic controls, at the end of the observation period (PI day 14: mortality, $70 \%$ vs. $20 \%$; mean \pm SEM SLE scores, $2.69 \pm$ 0.08 vs. $0.6 \pm 0.05 ; P<0.001$ for both comparisons).

To determine the effect of the differential mortality in the two groups, the SLE scores were analyzed in two ways: all animals (scores from all animals alive at each time point) and surviving animals only (scores from only the animals that survived to the end of the observation period). As seen in Figure $1 \mathrm{~A}$, the means for all animals and surviving animals were indistinguishable.

\section{TUNEL Assay}

Apoptotic cells were scant to nonexistent in the corneas of RNase L-null mice infected with HSV-1. TUNEL-positive cells were not found in the corneal sections 6 hours after inoculation (Fig. 2A) and only a few TUNEL-positive epithelial cells $(0.8 \pm 0.6$ per $400 \times$ field $)$ were detected in a small number of sections ( 4 of 60) at 18 hours (Fig. 2B). Apoptotic keratocytes were not seen. In contrast, the HSV-1-infected congenic controls showed $2.9 \pm 1.3$ TUNEL-positive cells per $400 \times$ field, mostly in the epithelial cell layer, at 6 hours (Fig. 2C) and $5.8 \pm$ 1.2 apoptotic cells per field, located in both the epithelium and anterior stroma, at 18 hours after inoculation (Fig. 2D). The differences in the counts of TUNEL-positive cells between the RNase L-null and congenic control mice were significant at 6 $(P=0.004)$ and 18 hours $(P<0.001)$ after inoculation. At 18 hours, the percentage of apoptotic cells in the congenic controls ranged from approximately $15 \%$ to $30 \%$, based on each field containing 20 to 40 corneal cells. The apoptotic cells were located, for the most part, in the immediate perimeter around or directly under the infected corneal surface, indicating the possible protective function of apoptosis.

The positive controls (corneal scarification) showed apoptosis in both the epithelium and anterior stroma (6.2 \pm 1.1 TUNEL-positive cells per $400 \times$ field at 2 hours after scarification; Fig. 2E), similar in amount to that seen in the HSV-1infected congenic controls at 18 hours after inoculation (5.8 \pm $1.2 ; P=0.072$ ). The negative controls (mock infection) showed no apoptotic cells (Fig. 2F).

\section{Histology}

Microscopic evidence of epithelial damage indicative of HSV-1 replication was not found in either the RNase L-null corneal sections or the congenic control sections obtained 6 hours
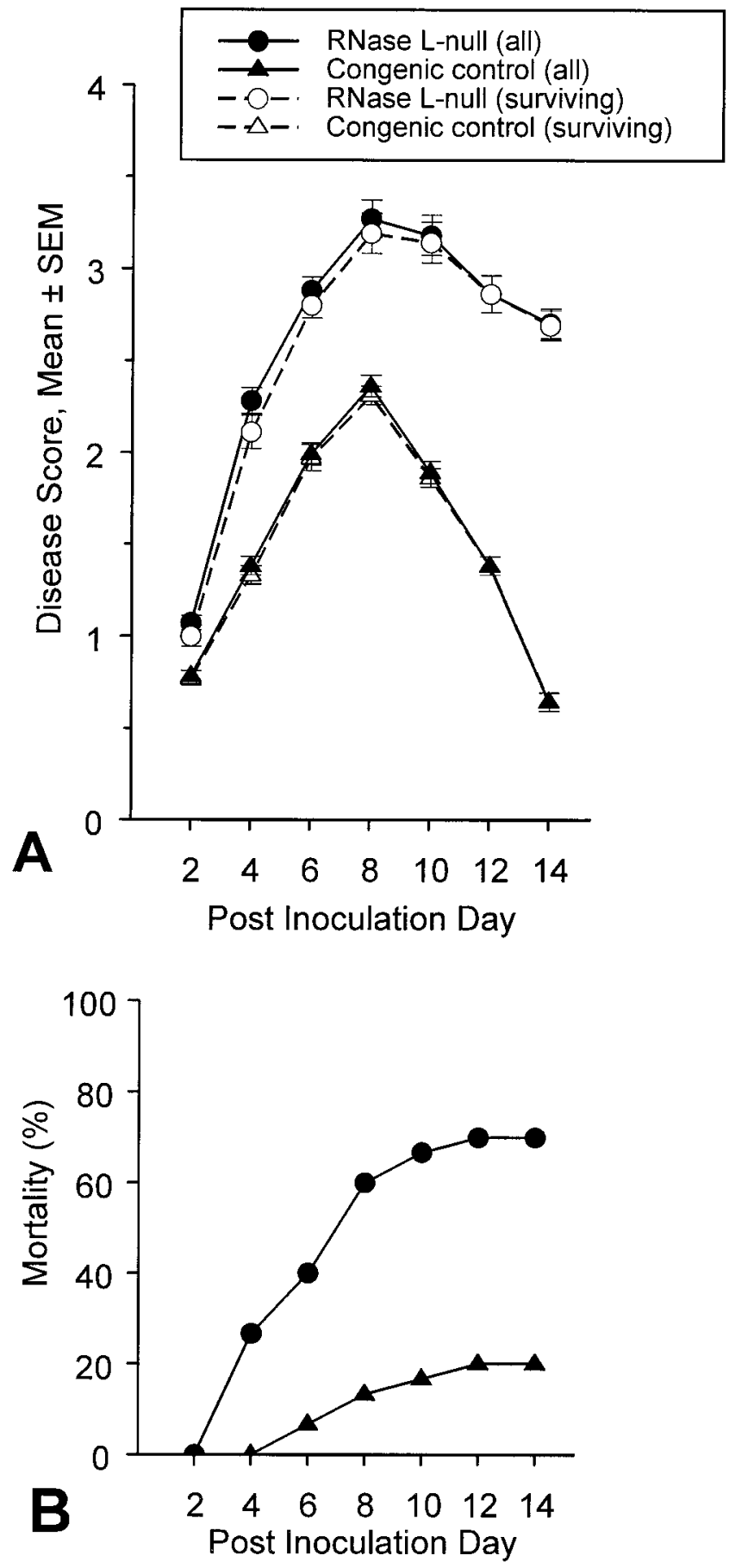

FIGURE 1. Severity of herpetic corneal lesions and mortality in RNase L-null mice and congenic controls. (A) Means ( \pm SEM) of slit lamp examination scores (scale 0 to 4 ) combined from three separate experiments, each involving 10 mice inoculated with $2.5 \times 10^{5}$ pfu/eye of HSV-1 McKrae and examined by slit lamp biomicroscopy every other day for 14 days, plotted versus PI day. Solid symbols represent data from all surviving mice at each observation point $(N=30,22,18,12$, 10,9 , and 9 RNase L-null mice and $30,30,28,26,25,24$, and 24 congenic control mice on PI days 2, 4, 6, 8, 10, 12, and 14, respectively). Open symbols represent data only from the mice that survived to the end of the observation period (day 14; 9 RNase L-null mice and 24 congenic controls). (B) Percent mortality of the two groups of mice during acute HSV-1 infection. 

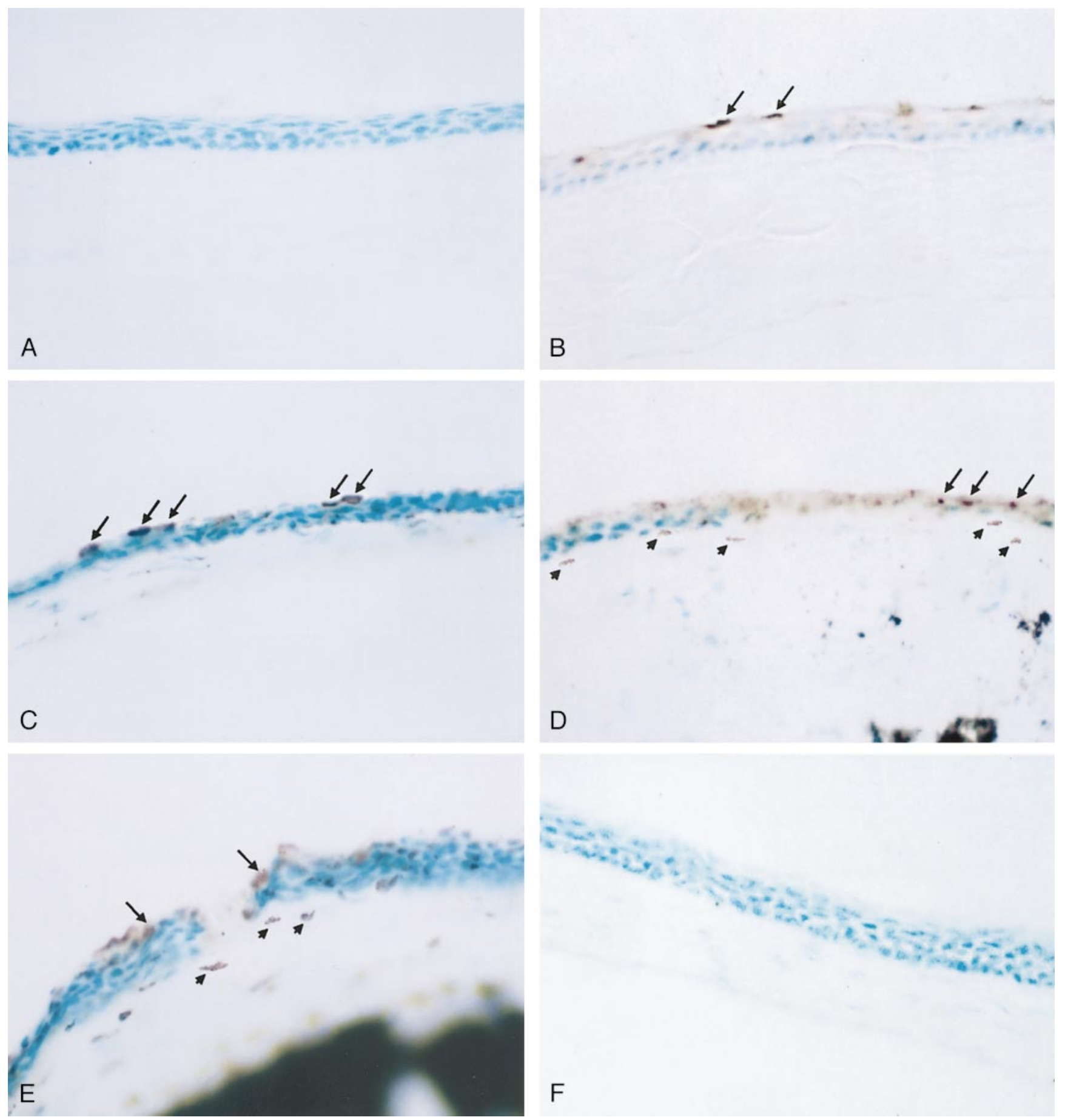

FIGURE 2. Corneal apoptosis detection by the TUNEL assay. (A) HSV-1-infected RNase L-null mouse cornea 6 hours after inoculation. DNA fragmentation in situ consistent with apoptosis (dark brown staining) is not detected in either the epithelial layer or the underlying stromal keratocytes. (B) RNase L-null mouse cornea 18 hours after inoculation. Only a few apoptotic epithelial cells are seen (arrows). (C) HSV-1-infected congenic control mouse corneal epithelial cell layer 6 hours after infection. Greater numbers of apoptotic epithelial cells are visible (arrows). (D) HSV-1-infected congenic control mouse corneal epithelial cell layer 18 hours after infection. Both epithelial cells (long arrows) and anterior stromal keratocytes (short arrows) show evidence of DNA fragmentation. (E) Positive control cornea (scarification only) 2 hours after scarification. Apoptotic cells are visible in the epithelium (long arrows) and stroma (short arrows). (F) Mock-infected negative control mouse cornea. TUNEL-positive cells are not found. Magnification, $\times 400$.

after inoculation. By 18 hours, microscopic epithelial damage was recognized in 8 of 60 (13.3\%) RNase L-null sections and 2 of $60(3.3 \%)$ congenic control sections $(P=0.034)$. Epithelial damage was not found in negative control (mock inoculation) corneas. All positive control (corneal scarification) corneas showed epithelial layer damage caused by needle scarification (data not shown).

Areas of sections with evidence of epithelial injury detected by light microscopy (if no epithelial injury, randomly selected areas) were examined by TEM for evidence of apoptosis in 

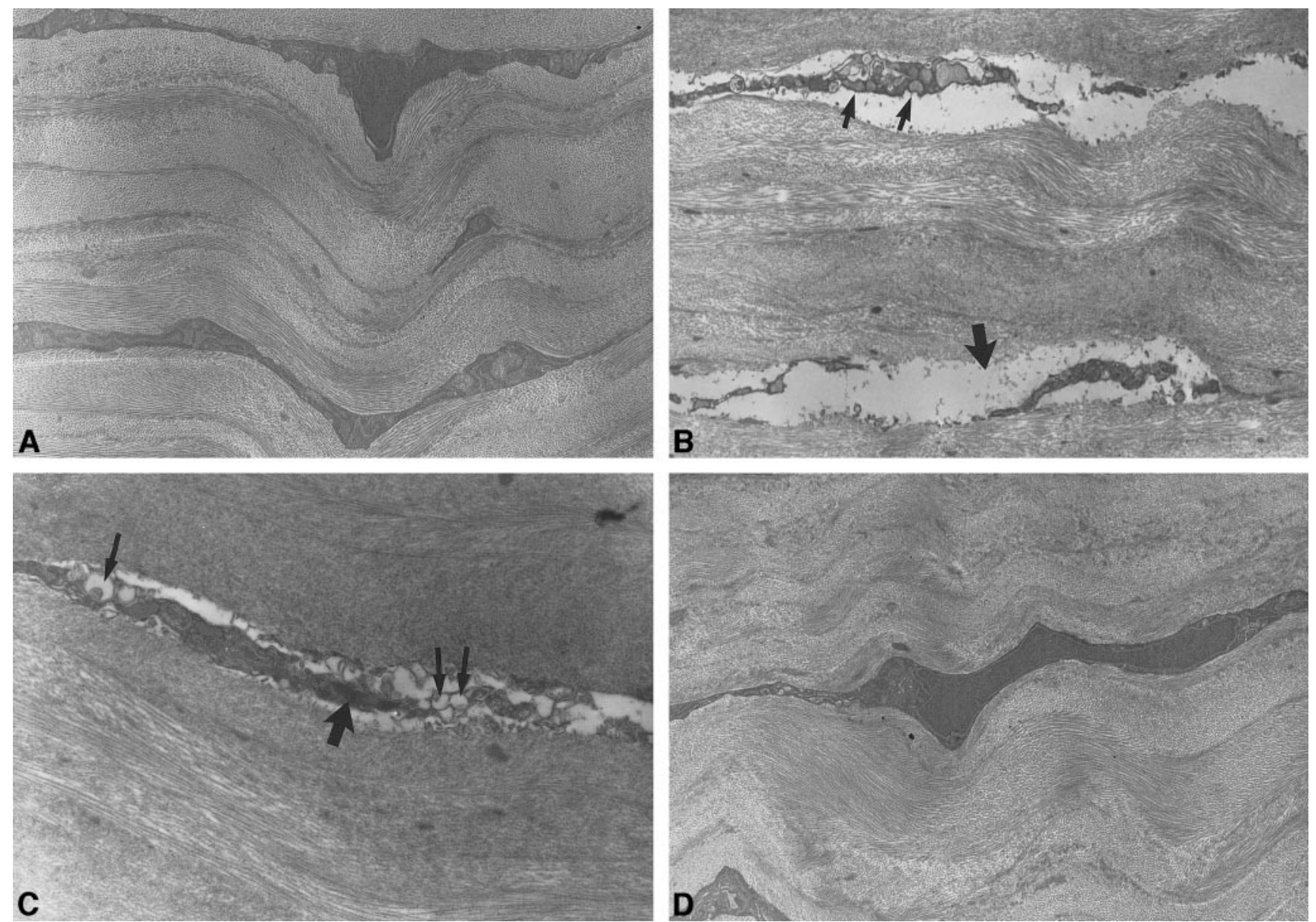

Figure 3. Transmission electron microscopic studies of keratocytes. (A) A mock-infected (negative control) cornea showing normal keratocytes and regular chromatin. (B) Two hours after corneal scarification, a positive control (scarification only) cornea shows signs of apoptosis, including cellular blebbing and numerous membrane-bound structures in a shrinking keratocyte (small arrows), as well as a keratocyte with a dramatically diminished cell volume (large arrow), in the superficial stroma. (C) At a very early stage of corneal infection (18 hours), a keratocyte in the anterior stroma of an HSV-1-infected congenic control mouse cornea shows dense chromatin condensation (large arrow) along the nuclear membrane associated with cellular blebbing (small arrows), with reduced cytoplasm, indicative of apoptosis. (D) At the same early stage of corneal infection (18 hours), an anterior stromal keratocyte in an HSV-1-infected RNase L-null mouse cornea shows no signs of apoptosis, with normal nuclear morphology and cytoplasmic volume. Magnification, $\times 6000$

underlying stromal keratocytes. Signs of apoptosis were not seen in the mock-infected corneas (Fig. 3A). Keratocytes in the HSV-1-infected congenic control corneas (18 hours) and the uninfected scarified control corneas (2 hours) showed apoptotic changes mostly in the anterior stroma (Figs. 3B and 3C). Approximately $5 \%$ of the keratocytes underwent changes characteristic of apoptosis, which include chromatic condensation, chromatic fragmentation, and cellular blebbing with formation of membrane-bound cell fragments. No apoptotic keratocytes were seen in the HSV-1-infected RNase L-null mouse corneas (Fig. 3D).

\section{Discussion}

The 2-5A system has been extensively investigated for its involvement in the antiviral effect of IFN by means of induction of apoptosis in vitro. $8,9,11,24,28,30,31$ In vivo study of the antiviral effect of the 2-5A system has been reported for encephalomyocarditis virus. ${ }^{24}$ The IFN family of cytokines is believed to play an important role in the clearance of virus from the eye. However, the molecular mechanism underlying the IFN-mediated antiviral effect in ocular HSV-1 infection is not well known. Our current experiments were undertaken to test our hypothesis that the $2-5 \mathrm{~A}$ system plays a role in the antiviral effect of IFN in the HSV-1-infected mouse eye by initiating keratocytic apoptosis.

Our clinical observations revealed that in comparison with the congenic controls, mice lacking the RNase L gene had exacerbated herpetic corneal lesions and increased mortality after HSV-1 infection. In the first set of experiments, we used a high viral titer $\left(2.5 \times 10^{7} \mathrm{pfu}\right.$ per eye $)$ to inoculate the mice. Although the mortality for RNase L-null mice was higher than that of congenic controls about halfway through the observation period, there was no significant difference in the severity of herpetic corneal lesions between the two groups at that time, possibly because of the small number of survivors available for evaluation. Also, the high dose of HSV-1 can perhaps override the $2-5 \mathrm{~A}$ system in the congenic controls, that is, the virus may have gained a substantial foothold before enough cells were able to establish an inhibitory state. When a 100-fold lower viral titer was used in the second set of experiments, the severity of corneal disease and mortality were significantly greater in the RNase L-null mice, compared with the congenic controls. Also, the RNase L-null mice developed more severe conjunctivitis, blepharitis, and viral endophthalmitis in comparison with the congenic control mice (data not shown). 
These findings demonstrate that the RNase L-null mice had significantly increased susceptibility to HSV-1, indicating that the absence of RNase L directly or indirectly increased viral pathogenesis and mortality during acute infection.

To study the underlying pathogenesis of the observed clinical features, we analyzed HSV-1-induced apoptosis in the cornea at very early stages of infection. Six hours after viral inoculation, signs of corneal epithelial lesions were not evident in either the RNase L-null mice or the congenic control mice. However, apoptotic cells could already be detected in the corneas of HSV-1-infected congenic control mice, suggesting that the signaling process mediating cell death precedes the microscopic epithelial damage caused by viral replication. Eighteen hours after inoculation, a few corneal epithelial lesions were noted in the congenic controls, whereas significantly more lesions were seen in the RNase L-null mouse corneas, indicating the early onset of HSV-1 epithelial effects in the vulnerable RNase L-null mice. Nevertheless, the RNase L-null corneas had significantly fewer apoptotic cells than the congenic control corneas, and those few cells were found only in the epithelial layer; in the congenic control corneas, apoptotic cells were detected in both the epithelial layers and the anterior stroma. Although we did not directly determine HSV-1 distribution in the cornea, our TUNEL assay and electron microscopic results showed that most of the apoptotic keratocytes were located beneath the HSV-1-infected epithelial area (as evidenced by epithelial damage), suggesting a protective role for apoptosis in HSV-1-infected corneas. ${ }^{13}$ As a defense mechanism, corneal cells are signaled to undergo apoptosis to prevent further spread of HSV-1 to the deeper stroma as well as higher levels of replication in the epithelium, followed by retrograde neuronal transport to the brain, causing death. Therefore, the significantly reduced apoptosis in the corneas of RNase L-null mice correlates with a decreased ability to resist HSV-1 infection, leading to increased severity of herpetic keratitis and high mortality.

The anti-HSV-1 potential of the 2-5A system has been studied in vitro. Fujihara et al. ${ }^{34}$ reported that introduction of 2-5A suppressed HSV-1 syncytium formation in BHK cell cultures and prevented the lethal effect of HSV-2 in infected guinea pigs. Cayley et al. ${ }^{35}$ showed that HSV can induce RNase $\mathrm{L}$ inhibitors (2-5A-related compounds) and that RNase $\mathrm{L}$ activation, as determined by rRNA cleavage, was minimal in IFNtreated, HSV-infected Chang cells. However, the possibility exists that early, localized activation of RNase L, not detected by the methods used, could be important. Khabar et al. ${ }^{36}$ reported that the absence of the PKR gene did not compromise the anti-HSV-1 activity of IFN in mouse embryo fibroblasts. However, when both the PKR gene and the RNase L gene were absent, the anti-HSV-1 activity of IFN was reduced by about fivefold, indicating that PKR and RNase L cooperate in some way to provide the anti-HSV-1 effect of IFN.

Other mechanisms, aside from apoptosis induction by RNase L, cannot be ruled out. For example, the activation of RNase L in infected cells could simply halt the infection without requiring induction of apoptosis. Also, it is possible that both apoptosis and another mechanism are involved. In addition, effects of RNase L on cytokine production and MAPKs that could be responsible for enhanced innate or adaptive immune responses against HSV-1 have been reported by Iordanov et al. ${ }^{37}$

In another study, intracerebral inoculation of the KOS strain of HSV-1 was lethal for both wild type and RNase L-knockout mice within 8 to 10 days. ${ }^{17}$ Therefore, the effect of RNase $\mathrm{L}$ is no longer observed when the ocular route of infection is bypassed. These results support the idea that the antiviral function of RNase L is to suppress the spread of HSV-1 through apoptosis. However, alternative explanations, including differences in viral doses and virus strains, are also possible.

In summary, our data show that mice lacking RNase L have significantly increased susceptibility to ocular HSV-1 infections. Our study provides the first in vivo evidence that the $2-5 \mathrm{~A}$ system could be important for controlling viruses other than picornaviruses (such as encephalomyocarditis virus). Alternative possibilities, such as contributions from unknown genetic differences in the RNase L-null mice, cannot be completely ruled out, however. Further experiments, including immunopathologic studies of ocular and brain tissues and determination of local and systemic immune responses in RNase L-null mice after HSV-1 infection, could help to elucidate the activity of the $2-5 \mathrm{~A}$ system during viral infection.

\section{Acknowledgments}

The authors thank Richard J. O'Callaghan, Mary E. Marquart, and Bryan M. Gebhardt for their editorial advice on this manuscript. Lia Pedroza provided technical assistance with the transmission electron microscopy.

\section{References}

1. Kaufman HE, Rayfield MA, Gebhardt BM. Herpes simplex viral infections. In: Kaufman $\mathrm{HE}$, Barron $\mathrm{BA}$, McDonald $\mathrm{MB}$, eds. The Cornea. Boston, MA: Butterworth-Heinemann; 1998:247-277.

2. Pepose JS, Leib DA, Stuart PM, Easty DL. Herpes simplex virus diseases: anterior segment of the eye. In: Pepose JS, Holland GN, Wilhelmus KR, eds. Ocular Infection and Immunity. St. Louis, MO: Mosby; 1995:905-932.

3. Silverman RH, Cirino NM. RNA decay by the interferon-regulated 2-5A system as a host defense against viruses. In: Morris DR, Harford JB, eds. mRNA Metabolism and Post-Transcriptional Gene Regulation. New York: John Wiley Liss; 1997:295-309.

4. Kerr IM, Brown RE. pppA2' $5^{\prime} \mathrm{A} 2^{\prime} \mathrm{p} 5^{\prime} \mathrm{A}$. An inhibitor of protein synthesis synthesized with an enzyme fraction from interferontreated cells. Proc Natl Acad Sci USA. 1978;75:256-260.

5. Pavlovic J, Staeheli P. The antiviral potentials of $\mathrm{Mx}$ proteins. J Interferon Res. 1991;11:215-219.

6. Williams BRG. The role of the dsRNA-activated kinase, PKR, in signal transduction. Semin Virol. 1995;6:191-202.

7. Vilcek J, Sen GC. Interferons and other cytokines. In: Field BN, Knipe DM, Howley PM, eds. Fields Virology. Philadelphia: Lippincott-Raven; 1996:375-399.

8. Castelli JC, Hassel BA, Wood KA, et al. A study of the interferon antiviral mechanism: apoptosis activation by the $2-5 \mathrm{~A}$ system. $J$ Exp Med. 1997;186:967-972.

9. Diaz-Guerra M, Rivas C, Esteban M. Activation of the IFN-inducible enzyme RNase L causes apoptosis of animal cells. Virology. 1997; 236:354-363

10. Diaz-Guerra M, Rivas C, Esteban M. Inducible expression of the 2-5A synthetase/RNase $L$ system results in inhibition of vaccinia virus replication. Virology. 1997;227:220-228.

11. Castelli JC, Hassel BA, Maran A, et al. The role of $2^{\prime}, 5^{\prime}$-oligoadenylate-activated ribonuclease $\mathrm{L}$ in apoptosis. Cell Death Differ. 1998 5:313-320.

12. Player MR, Torrence PF. The 2-5A system: modulation of viral and cellular processes through acceleration of RNA degradation. Pharmacol Ther. 1998;78:55-113.

13. Wilson SE, Pedroza L, Beuerman R, Hill JM. Herpes simplex virus type 1 infection of corneal epithelial cells induced apoptosis of the underlying keratocytes. Exp Eye Res. 1997;64:775-779.

14. Aubert M, Blaho JA. The herpes simplex virus type 1 regulatory protein ICP 27 is required for the prevention of apoptosis in in fected human cells. J Virol. 1999;73:2803-2813.

15. Asano S, Honda T, Goshima F, et al. US3 protein kinase of herpes simplex virus type 2 plays a role in protecting corneal epithelial cells from apoptosis in infected mice. J Gen Virol. 1999;80:51-56.

16. Chou J, Chen JJ, Gross M, Roizman B. Association of a M(r) 90,000 phosphoprotein with protein kinase PKR in cells exhibiting en- 
hanced phosphorylation of translation initiation factor eIF-2 alpha and premature shutoff of protein synthesis after infection with $\gamma_{1}$ 34.5-mutants of herpes simplex virus 1. Proc Natl Acad Sci USA. 1995;92:10516-10520.

17. Leib DA, Machalek MA, Williams BR, et al. Specific phenotypic restoration of an attenuated virus by knockout of a host resistance gene. Proc Natl Acad Sci USA. 2000;67:6097-6101.

18. He J, Ichimura H, Iida $\mathrm{T}$, et al. Kinetics of cytokine production in the cornea and trigeminal ganglion of $\mathrm{C} 57 \mathrm{BL} / 6$ mice after corneal HSV-1 infection. J Interferon Cytokine Res. 1999;19:609-615.

19. Lausch RN, Su YH, Ritchie M, Oakes JE. Evidence endogenous interferon production contributed to the lack of ocular virulence of an HSV intertypic recombinant. Curr Eye Res. 1991;10[Suppl]: $39-45$.

20. Chen SH, Oakes JE, Lausch RN. Synergistic anti-herpes effect of TNF-alpha and IFN-gamma in human corneal epithelial cells compared with that in corneal fibroblasts. Antiviral Res. 1994;25:201213.

21. Hovanessian A. RNA-activated enzymes: a specific protein kinase and $2^{\prime}, 5^{\prime}$ oligoadenylate synthetases. J Interferon Res. 1991;11: $199-205$.

22. Silverman RH. 2-5A-dependent RNase L: a regulated endoribonuclease in the interferon system. In: D'Alessio G, Riordan JF, eds. Ribonucleases: Structures and Functions. San Diego: Academic Press; 1997:515-551.

23. Gribaudo G, Lembo D, Cavallo G, Landolfo S, Lengyel P. Interferon action: binding of viral RNA to the 40-kilodalton $2^{\prime}-5^{\prime}$-oligoadenylate synthetase in interferon-treated HeLa cells infected with encephalomyocarditis virus. J Virol. 1991;65:1748-1757.

24. Zhou A, Paranjape J, Brown TL, et al. Interferon action and apoptosis are defective in mice devoid of $2^{\prime} 5^{\prime}$-oligoadenylate-dependent RNase L. EMBO J. 1997;16:6355-6363.

25. Martinand C, Salehzada T, Sihol M, et al. RNase L inhibitor (RLI) antisense constructions block partially the down regulation of the 2-5A/RNase L pathway in encephalomyocarditis-virus-(EMCV)-infected cells. Eur J Biochem. 1998;254:248-255.

26. Li XL, Blackford JA, Hassel BA. RNase L mediates the antiviral effect of interferon through a selective reduction in viral RNA during encephalomyocarditis virus infection. J Virol. 1998;72:2752-2759.

27. Marie I, Rebouillat D, Hovanessian AG. The expression of both domains of the $69 / 71 \mathrm{kDa} 2^{\prime}, 5^{\prime}$ oligoadenylate synthetase gener- ates a catalytically active enzyme and mediates an anti-viral response. Eur J Biochem. 1999;262:155-165.

28. Matitra RK, Silverman RH. Regulation of human immunodeficiency virus replication by $2^{\prime}, 5^{\prime}$-oligoadenylate-dependent RNase L. $J$ Virol. 1998;72:1146-1152.

29. Martinand C, Montavon C, Salehzada T, Sihol M, Lebleu B, Bisbal C. RNase $\mathrm{L}$ inhibitor is induced during human immunodeficiency virus type 1 infection and down regulates the 2-5A/RNase $\mathrm{L}$ pathway in human T cells. J Virol. 1999;73:290-296.

30. Zhou A, Paranjape JM, Hassel BA, et al. Impact of RNase L overexpression on viral and cellular growth and death. $J$ Interferon Cytokine Res. 1998;18:953-961.

31. Castelli JC, Wood KA, Youle RJ. The 2-5A system in viral infection and apoptosis. Biomed Pharmacother. 1998;52:386-390.

32. Wilson SE, He YG, Weng J, et al. Epithelial injury induces keratocyte apoptosis: hypothesized role for the interleukin-1 system in the modulation of corneal tissue organization and wound healing. Exp Eye Res. 1996;62:325-337.

33. Mera R, Thompson HW, Prasad C. Analyzing data from experiments in which the outcome is time to an event. Nutr Neurosci. 1998; 1:319-326.

34. Fujihara M, Milligan JR, Kaji A. Effect of $2^{\prime}, 5^{\prime}$-oligoadenylate on herpes simplex virus-infected cells and preventive action of $2^{\prime}, 5^{\prime}$ oligoadenylate on the lethal effect of HSV-2. J Interferon Res. 1989;9:691-707.

35. Cayley PJ, Davies JA, McCullagh KG, Kerr IM. Activation of the ppp $\left(\mathrm{A}^{\prime} 2 \mathrm{p}\right) \mathrm{nA}$ system in interferon-treated, herpes simplex virus-infected cells and evidence for novel inhibitors of the ppp (A2'p) nA-dependent RNase. Eur J Biochem. 1984;143:165-174.

36. Khabar KSA, Dhalla M, Siddiqui Y, et al. Effect of deficiency of the double-stranded RNA-dependent protein kinase, PKR, on antiviral resistance in the presence or absence of ribonuclease L: HSV-1 replication is particularly sensitive to deficiency of the major IFNmediated enzymes. J Interferon Cytokine Res. 2000;20:653-659.

37. Iordanov MS, Paranjape JM, Zhou A, et al. Activation of p38 mitogen-activated protein kinase and c-Jun $\mathrm{NH}_{2}$-terminal kinase by double-stranded RNA and encephalomyocarditis virus: involvement of RNase L, protein kinase R, and alternative pathways. $\mathrm{Mol}$ Cell Biol. 2000;20:617-627. 